\title{
The Racial Imagination of the Lindy Hop from the Historical Standpoint - Comments and Corrections
}

\author{
American Allegory: Lindy Hop and the Racial Imagination by Black Hawk Hancock. Chicago, IL, University of \\ Chicago Press. 2013.
}

Review with historical additions written by Harri Heinilä, Doctor of Social Sciences, the University of Helsinki

Dr. Black Hawk Hancock discusses in his study how an originally African-American jazz dance, the Lindy Hop, which he calls also a swing dance, was modified by mainly white enthusiasts who discovered the dance starting from the 1980s, and how particularly the 1990s enthusiasts obscured the roots of the dance by appropriation, whitewashing, and ignoring its African-American aspects.

Dr. Hancock did a doctoral dissertation on the Lindy Hop and the racial imagination in 2004. It was published in the form of a book in 2013. The study belongs to the field of sociology, and as such it is not a historical study of the subject. Dr. Hancock discusses also the Lindy Hop history and refers to it on many occasions, so history plays a significant part in his study.

I will present comments and corrections mainly from the historical standpoint to this sociologically remarkable and groundbreaking study which with respect to the history of the original Lindy Hop, which means the Lindy Hop before the 1980s, misses the mark quite often. Because the study was published for the first time in 2004, it is clear that the historical analysis was based on the studies which existed at the time. Nowadays, there are considerably more studies about the history of the Lindy Hop available. Thus, the 2013 book could have been an updated version of the dissertation with appropriate corrections. But it is also about the problematic use of historical studies which were available before his dissertation.

\section{New York Scene}

First of all, I'm surprised that Dr. Hancock obviously never visited New York for his dissertation. That becomes clear when reading his study, and there particularly page 7 . He mentions on page 10 that "the swing revival" happened in New York, Stockholm, Los Angeles, and London in the 1980s, which I agree. All the remarkable scholars and enthusiasts of the Lindy Hop have been in New York for searching and interviewing those who defined various styles of the Lindy Hop between the 1930s and the 1980s revival[1]. It could be argued that no one who takes the Lindy Hop and its history seriously can bypass New York. It seems that the New York scene did not similarly affect Dr. Hancock as it did many others before him.

The dismissal of the New York scene leads to problems in his historical analysis, and it also affects other analysis. Two of the most significant problems in the historical analysis are his explanation of the birth of the Lindy Hop and its continuation after the 1940 s.

\section{The Birth of the Lindy Hop}

Dr. Hancock states on page 11 that "Marshall Stearns gives credit to Shorty George Snowden for naming the Lindy Hop" by quoting Stearns in his groundbreaking study Jazz Dance in 1968. Actually, Stearns gives credit to Snowden for the naming and creating the Lindy Hop which happened in Harlem's Manhattan Casino (Rockland Palace) dance marathon between June and July 1928.[2]

That had become clear to Dr. Hancock if he had quoted more Stearns who states in Jazz Dance that "Snowden's mild conviction that he invented the breakaway and thereby the essence of the Lindy is probably true for his time and place." Stearns continues that Snowden practically rediscovered the Breakaway in the dance marathon where Snowden was claimed to have named the Lindy Hop.[3] Dr. Hancock was possibly confused by Snowden's explanation to Stearns that the basic step of the Lindy Hop was called the Hop for a long time before the dance marathon.[4] Thus, at first glance, it looks like Snowden underplayed his role as the creator of the Lindy Hop, but Snowden's statement refers to the fact that he used already existing elements of dancing when he and his partner had an accident in the dance marathon, which led into the temporary separation of partners, and Snowden and his partner, Mattie Purnell, invented the basic principle of the Lindy Hop by "rediscovering" the Breakaway pattern.[5] That started the process which led into the acknowledgement of the Lindy Hop.[6] Thus, Snowden and Purnell are the creators of the Lindy Hop. 
Connecting African-American George Snowden firmly to the creator role would have helped Dr. Hancock to establish the Lindy unequivocally as an original African-American, Harlem-born dance. Marshall Stearns refers in Jazz Dance to the fact that also whites claimed to have invented the Lindy Hop[7]. The latest research has brought out the fact that there existed various Lindy Hop dances since Charles Lindbergh did his famous flight over the Atlantic in May 1927. These Lindy Hop dances were not connected to Harlem, and likely they were not invented by African-Americans.[8] Leaving the field open for interpretations of the origin of the Lindy Hop endangers Dr. Hancock's main mission to show that the Lindy Hop was not acknowledged correctly by the white revivalists. Without Snowden and Purnell as the creators, it would be possible to claim that the Lindy Hop was not originally from Harlem, and an African-American invention. Given Harlem as the birthplace of the Harlem Lindy Hop, it could still be claimed that Harlemites only plagiarized whites as to the naming of the Lindy.

Thus, obscuring the origin of the Lindy Hop as a dance created by unknown or unnamed Harlemites without showing more precisely which of them really created the dance makes it possible to claim that actually it was white people who invented the dance.[9] In the case, it would be difficult to show that white revivalists recognized the Lindy Hop in a wrong way if it was not originally from Harlem and not even invented by African-Americans. In addition to the issue of plagiarism, leaving only the role in the naming to Snowden does not help either because there does not exist proper evidence for that.

Snowden purportedly named the dance in the dance marathon between June and July 1928, but there was no mention of the Harlem Lindy Hop in the US press until September 1928. The gap between the dance marathon and the first use of the term does not make sense if Snowden really named his invention as the Lindy Hop between June and July. It is also unclear whether it was Snowden or somebody else who named the dance for the newspaper articles and advertisements in which the term was used for the first time in September.[10] As this is based on current research, Dr. Hancock was not aware of this when he did his dissertation. However, he should have been aware of Dr. Howard Spring's study in 1997 in which Dr. Spring brought out the fact that the term in connection with the Harlem Lindy Hop was used for the first time in newspapers in September 1928.[11]

African-Americans and Harlemites, Snowden and Purnell, recognized as the creators of Harlem's Lindy Hop is the best guarantee of an African-American origin of the Lindy Hop.

\section{Continuation After the 1940s}

Dr. Hancock's study is based on the assumption that the Lindy Hop's perception was changed drastically by the Lindy Hop revival/Swing revival, as he calls the period between the 1980 s and especially the 1990s when mainly white "swing dance" enthusiasts discovered the Lindy Hop which was considered to have laid dormant since its heyday in the 1930s and the 1940s, or at the latest when famous Savoy Lindy Hopper Frankie Manning retired from professional Lindy Hop dancing in the middle of the 1950s and Harlem's Savoy Ballroom was closed in 1958. According to Hancock, while the dance lost its popularity among mainstream white society, the Lindy Hop never died in AfricanAmerican communities as it mutated to other African-American dances like Boppin', Hand Dancing and Steppin'.[12]

As I agree that the dance mutated and the interest waned during the decades before the 1980s revival, Dr. Hancock's basic assumption of the dormancy is challenged by the fact that the Lindy Hop actually never disappeared in Harlem and New York.

Savoy Lindy Hoppers trained new generations in the Lindy Hop, in particular, for the Daily News-sponsored Harvest Moon Ball contest in the New York metropolitan area between 1935 and 1974, and for its continuations: the Harvest Moon Ball contest between 1976 and 1983, and Mama Lou Parks Duncanson's International Harvest Moon Ball contest between 1980 and 1989.[13] The latter two of the contests happened at the same time with the beginning of the revival. The Lindy Hop was still practiced in its all three modes: social, performance and competition by both AfricanAmerican and white dancers between the 1950s and the 1980s.[14]

There is no reason to state that the Lindy Hop laid dormant at the latest after the closing of Harlem's Savoy Ballroom. Its popularity waned, but it was maintained by various African-American and white dancers and dance groups before the revival. Thus, Dr. Hancock should have asked what the revivalists between the 1980s and the 1990s exactly revived and discovered? Many of the Lindy Hop Old-timers were active, and even Frankie Manning who worked in the post office still danced socially during the decades of the "dormancy"[15]. Had Dr. Hancock examined the decades between the 1950 s and the 1980 s, he would have realized that there was nothing else to revive but the mainstream interest in the 
Lindy Hop. Because of that, in fact, the Lindy Hop/Swing revival should be called the revival of the interest in the Lindy Hop.

\section{"Whitewashing" of the Lindy Hop}

One sign of the "whitewashing" of the Lindy Hop is the different terminology between the enthusiasts and Old-timers. On page 157, Dr. Hancock quotes Savoy Lindy Hopper and Jazz dancer Norma Miller who stated that Swing dance was called (the) Lindy (Hop) in the past when she danced at the Savoy Ballroom. On pages 139-140, he suggests that the revivalists used racially "neutral" terms like 'swing dance' and 'swing dancing' for decontextualizing and deracializing the Lindy Hop. According to him, in the late 1990s, it looked like it was promoted only "the teaching of 'Swing dancing' ". At the time, the revivalists began to distinguish the "authentic style" of "Swing dancing" from other "swing dances" for two reasons: because the famous Gap ad in which it was performed the "authentic style" increased the popularity of this style of "Swing dancing", and because the revivalists wanted to distinguish the Lindy Hop from "Jive" which was "the more formal version of "Swing dancing"“. As the result, the revivalists started to use the term 'the Lindy Hop' and 'Savoy Style Lindy Hop'. Thus, the proper name of the dance reemerged. On the contrary, jazz dance historian Terry Monaghan argues that it was the 1980s revivalists who put the term 'lindy hop' back into general use, and in effect acknowledged the African-American authorship of the dance[16].

Delving deeper into this issue could have shed more light on it. It is true that the use of the terms 'swing dance' and 'swing dancing' exploded between 1990 and 1999 as based on the use in the white mainstream press and compared to the decades before the 1990s. The explosion of the use of the terms 'swing dance' and 'swing dancing' in the mainstream press still continued through the 2000 s, even so that the usage tripled by 2015 . The usage of the terms in the African-American press at the same time and the decades before was only minimal compared to the mainstream press.[17] It seems that Harlemites were not for 'swing dancing'.

This is reinforced by Terry Monaghan who claimed that Harlemites considered a swing dancer the dancer who could not lindy hop properly. Monaghan's claim is supported by the fact that Harlem's Apollo Theatre organized dance contests for both whites and African-Americans between 1934 and 1935. The white contests were called 'Swing the Lindy Night' and the African-American contests were called 'Lindy Hop Night'.[18] Using the prefix 'swing' for the white contests possibly was meant to imply that whites did not do the pure Lindy Hop at the time.

Thus, combining this with Dr. Hancock's analysis, the revivalists, who supposedly used the 'swing dance'-based terminology for avoiding racial meanings, ironically used racially loaded and derogatory terminology.

The statement is confused by the fact that the Lindy (Hop) dancers on the West Coast referred to their dancing as 'swing' and 'swing dance'. [19] Because the dancers were mainly white, it could be questioned whether the New York and East Coast revivalists borrowed the terminology from the West Coast usage.[20] Anyway, also this supports the fact that mainly whites used the terms.

Another terminological issue concerns the term 'jitterbug'. Dr. Hancock argues on page 144 that the term jitterbug was a white name for the Lindy Hop, while on page 13 he confirms the sameness between Jitterbug and the Lindy Hop by quoting Frankie Manning who explained that Jitterbug and the Lindy Hop meant the same dance[21]. Indeed, Dr. Hancock disagrees with Manning to some degree because on page 172 he calls Jitterbug as one of "the basic six-count traditional Swing dances". By doing a proper etymological analysis of the origin of the terms, the real racial identity of the terms could have been examined. Terry Monaghan argued that the term 'jitterbug' could have been derived from Cab Calloway's usage of the term 'jitter-sauce', and there was the 'Jitter Bug Club' in Harlem in the 1930s, where the term could have been originated as well.[22] Anyway, the terms 'jitter bug' and 'jitterbug' were used in connection with Harlemites in the 1930s, and the term 'jitterbug' was connected to Savoy Lindy Hoppers by the end of the 1930s.[23] Thus, the term could have originated from either African-American or white sources, or both.

This is also confused by the fact that Chicago's Savoy Ballroom dancers were referred to by the term 'jitterbug' in the African-American press in the 1930s and the 1940s[24]. Dr. Hancock, who examined also African-American Steppin' dancers in Chicago, does not discuss this and Chicago's Savoy Ballroom at all, although the ballroom was located in Southside Chicago, in an African-American area.[25] At one point, Chicago dancers were claimed to be even better than Whitey's Lindy Hoppers[26], which emphasizes their importance. Indeed, this claim is very arguable when considering the success of Whitey's Lindy Hoppers and also contrary claims of the superiority of Whitey's Lindy Hoppers compared to their Chicago counterparts.[27] Anyway, the term 'jitterbug' was not used only by whites, and 
there is evidence for its African-American origin. Given Dr. Hancock's claim of 'jitterbug' as a "white" term, it could be argued that African-Americans copied whites when they started to use the term 'jitterbug'.

Another problem concerning "whitewashing”, which Dr. Hancock fails to discuss appropriately, is correct music for lindy hopping. He describes on page 91 how dancers "congregated in a "jam" circle” when Benny Goodman's "Sing Sing Sing” was played. Dr. Hancock obviously was not aware of Frankie Manning's opinion of the song. Manning stated bluntly, "Dancers today like doing jam circles to "Sing, Sing, Sing," but we never jammed to music like that. We didn't even like "Sing, Sing, Sing." There was too much drum." He also explained that he danced to fast and moderate tempo songs if they were swinging and he liked them.[28] Similarly to Manning, Albert 'Al' Minns stressed Swing as the music for the Lindy hop when he gave a lesson in music to a revivalist Robert P. Crease in the 1980s, who inadvertently played Dixieland jazz as good swing dancing music.[29] As based on my experience, "Sing Sing Sing" and Dixieland jazz at the expense of Swing music are frequently played in "swing dance" events in which mainly white lindy hoppers participate.

Thus, Dr. Hancock almost totally bypasses one of the most important pieces of evidence for "whitewashing" of the Lindy Hop. Instead of discussing the issue, on pages 91-93, he criticizes the "jam circle" displays and the teachings of traditional jazz steps like 'pimp walk' and fishtail as a form of minstrelsy and derogatory expressions. On the other hand, on page 76, he connects 'Pimp-walk' as a part of "African based dance", which confuses the reader more. Overall, this obscures and even ridicules his idea of the "whitewashing". Practically, the "jam circles" which were usually known as 'circle(s)' in the past are one of the most important expressions of the current Lindy Hop scene, which can be associated with Harlem's Savoy Ballroom. Savoy Lindy Hoppers danced usually in the Corner and there in a circle formation called the Circle at the Savoy. Sometimes, the Savoy Ballroom was full of circles. So, also other Savoy dancers than Savoy Lindy Hoppers danced in circles. Circles were part of the Savoy tradition, and they were based on African-American dance traditions like circle dancing and "cutting contests".[30] In order to criticize the circles and traditional jazz steps, Dr. Hancock should criticize the original Lindy Hop culture and African-American jazz dance which the circles and steps originated from.

He also confuses Modern dance-based "modern jazz dance" with "authentic" (original) jazz dance. On pages 132 - 133 , Dr. Hancock describes in detail an episode where his dance partner refused to participate in a basic jazz class by the Joel Hall Company, although the instructor of the class invited her to participate in it for free. Dr. Hancock criticizes his partner who did not want to participate in the class because she as a white person was afraid of being compared to skilled African-American dancers, whom the company and the class consisted of. As Dr. Hancock notices appropriately that the episode was ridiculed by the fact that his partner taught and performed African-American dances to whites, but she did not want to participate in a class taught by African-Americans, he misses the point that the Joel Hall Company taught Modern-dance based "jazz dance" which had nothing to do with original jazz dances.[31] Maybe this also affected his dance partner. In fact, It could be asked why African-American dancers were so interested in "white" Modern dance-based dance forms[32], instead of learning "authentic" African-American jazz dances like the Lindy Hop?

He addresses the issue to some degree in a subchapter 'Blaming the Victim', on pages 132-139, by asking from both black (the US and the non US people of color) and white dancers why African-Americans are not willing to learn the Lindy Hop anymore. He got varied answers from both sides. It seems that white dancers considered in general that African-Americans were just not interested in old dance forms and wanted to move on to new dances. Black dancers emphasized as the reason the lack of interest in the African-American history and culture of the Lindy Hop and original African-American dances among people of color. As on page 139 he refers to the "white" domination and power structure, which maintain "racial divisions" in the US society, and which also affects African-American lindy hoppers because the Lindy Hop is dominated by whites, he could have delved deeper into the subject from the AfricanAmerican point of view. Now, he ignores the involvement of the Harlem Renaissance Movement which neglected the Lindy Hop and other jazz dances as "low culture" and did not acknowledge the Lindy as an important cultural achievement. The movement practically acknowledged the dance only as a fad, and therefore it was not culturally remarkable.[33] This may explain to some degree why original "authentic" African-American jazz dances have been rejected by so many African-Americans who are more interested in "modern” dances like Hand Dancing and Steppin' including Hip Hop dancing which also is a continuation of "authentic" jazz dance[34].

Another historically critical point which Dr. Hancock mentions, but he fails to discuss correctly, is how Swing culture, particularly during so-called Swing Era in the 1930s and the 1940s, supported multiculturalism and racial mixing between African-Americans and whites. He mentions on page 13 that the Lindy Hop was danced by African-Americans and whites in the 1930s and the 1940s, but only occasionally mixing. He also quotes Norma Miller who argues that 
African-Americans did not want to let whites take their dance implying a claim that whites were not part of the AfricanAmerican dance activity which Ms. Miller represented.

He could have added to the analysis that actually whites were part of Herbert White's dance group which usually is known as Whitey's Lindy Hoppers, and consisted mainly of African-American dancers. There were at least three white dancers in the group who performed successfully along with their African-American colleagues[35]. Racially mixed dancing was the fact at the Savoy Ballroom. In general, Swing culture was racially mixed before World War II. Because of the Swing culture, the US overall was culturally inclusive, in particular, between 1935 and 1942.[36]

His lack of knowledge of African-American culture and history shines through when on page 130 he describes episodes where allegedly "racist" terminology was used by teachers and dancers. He quotes various white lindy hoppers who commented their mistakes by using phrases like 'I can't get this! I'm so white!' and 'Oh my God, I feel so white." He did not seem to be aware of the fact that also African-Americans commented other African-Americans with similar phrases when they did not dance in the way they are supposed to.[37] As I agree with him that using the phrases marks racial identity and leads to think that the "white" identity in dancing is inferior, he misses the point that in this respect both whites and African-Americans seem to think in the same way, but likely for different reasons considering the long history of slavery in the US. That means, arguably, African-Americans dismiss "white domination" by using the phrases, and thus condemning African-Americans who dance like their "white" counterparts, but to whites the phrases mean only bad dancing. It could also be argued that a "white" identity is not usually appreciated in the Lindy Hop, which also Dr. Hancock's interviews with both white and African-American dancers point to[38].

Similarly, he seems to miss the point when he quotes Steven Mitchell, who is widely condemned in the "swing dance" community because of his alleged sexual assaults on dancers.[39] On page 106, Mitchell is quoted stating, "There is no sex in the dance" referring to the lack of passion between a man and a woman in dancing. Dr. Hancock interprets this to mean that "the blackness of the dance" has been removed because of whites both desire the dance and feel reserved when dancing. As a result of this, whites deny "the sexuality of the dance." On page 99, Mitchell is quoted stating the contrary, "people have taken [the dance] so far out, it's not even dancing any more. It's just sex out there..." This makes the reader to wonder what happened between the interviews: it looks like a pseudo analysis unfolded under Dr. Hancock's nose.

On page 39, he defines four of the most fundamental aspects of the Lindy Hop. He does not include 'rhythm' to them, although he mentions it later when defining what is the Lindy Hop. That is a significant difference compared to the eminent Savoy Lindy Hoppers, Frankie Manning, who represented the Second Generation of Savoy Lindy Hoppers, and George Sullivan, who represents the Third Generation of Savoy Lindy Hoppers. Both of them have stressed rhythm as the most important aspect in the Lindy Hop.[40] In regard to Manning and Sullivan's opinion, when discussing "whitewashing" of the Lindy Hop, correct rhythm should be the main concern. A famous African-American entertainer Ethel Waters stated in her autobiography that "Most of colored people can't bear to dance with white folks. Invariably whites dance in a broken rhythm, don't listen to music and the count. They are off the beat most of the time."[41] On page 41, Dr. Hancock explains how dancers can "play" with the music by being " "on" the beat and "off" the beat". He does not mention that dancing on the "off" beat is actually a basis for the original Lindy Hop rhythm[42]. What is the off beat has not been clear to many of current enthusiasts.[43] Therefore, once again, Dr. Hancock bypasses a sign of current "whitewashing" in the Lindy Hop.

\section{Commodification and History}

In the subchapter 'Commodification', Dr. Hancock argues that whites have produced a "white" version of "blackness" to entertain white people. The Lindy Hop has been turned into a consumer good in the marketplace. As I agree with him on the "white" version, he mistakes the African-American Lindy Hop history. That happens when he states that the dance went underground for a long time, and it was turned into "a consumer good" by the revivalists. As I stated before, the Lindy Hop never disappeared or laid dormant in Harlem. The popularity of the dance waned during the decades after its heyday in the 1930s and the 1940s. After that the Lindy Hop was kept alive by African-Americans and whites, who also made their living out of it as they did during the heyday. It is arguable how correctly they were paid for dancing, but basically the Lindy Hop was "commoditized" by African-Americans and also whites decades before the revival in the 1980s.[44] However, I agree with Dr. Hancock that the revival created dance teachers whose knowledge was based on a very short practice.

His lack of knowledge of the history comes out again when he relies on the idea that the dance should be taught in classes, instead of learning the Lindy Hop by watching and imitating dancers on the dance floor as it usually used to be 
in the past as to the Savoy Ballroom scene[45]. This fixation with dance classes prevails in the "swing dance" community, so Dr. Hancock only follows the latest trend[46].

On the other hand, it would be wrong to say that there were no "classes" by Savoy dancers. Some of them had even dance schools for a while[47]. However, for the most part, when Savoy Lindy Hoppers taught newcomers to dance, it was more about mentoring than "teaching classes" per se[48]. The Savoy Ballroom and its Lindy Hop scene were part of the Harlem community where dancers traded steps even on the street corners[49]. Basically, the community taught you a step if you did not know it.

This type of a communal aspect has disappeared to a great extent because it is supposed that current dancers learn to dance in dance classes which are organized by organizations like dance schools and dance camps, and individual teachers[50]. The school system standardizes the Lindy Hop and practically destroys real social dancing which emphasized togetherness of couples on the dance floor: everybody danced on the "same" beat at the Savoy. Now, the couples practically compete with each other because schools teach mainly performance mode of lindy hopping with big movements and emphasis on "correct" patterns, instead of rhythm which creates harmony between the couples which try to follow music rather than do the patterns and steps in the way they were taught in classes[51]. It comes out both implicitly and directly in the interviews that Dr. Hancock conducted and also in his comments that in order to learn to dance socially, dancers have to dance on the social dance floor. The dance classes cannot teach real social dance.

The class-based teaching system has also been criticized by those who frequented the Savoy Ballroom. The primary criticism has been that dance classes are "feel good sessions" without the same seriousness which Savoy Lindy Hoppers represented.[52]

I'm not entirely convinced of Ryan Francois' comment on the white revivalists on page 113. He is quoted concerning an incident where the revivalists pleased Norma Miller and Frankie Manning only because they wanted to get Manning and Miller's ideas for creating "their own power structures" in the Lindy Hop world. According to Francois, he and Steven Mitchell were the only other two black persons, in addition to Manning and Miller, in the room where the revivalists met Manning and Miller, and the only ones who did not attend to Manning and Miller in a disturbing way. It is possible that Francois mistook the situation because of enthusiasm which the revivalists expressed for the famous Savoy Lindy Hoppers[53]. It could be even argued that had African-Americans expressed similar enthusiasm for Savoy Lindy Hoppers, there were versatile African-American Lindy Hop communities around the US, in addition to Harlem. Arguably, the only Savoy Lindy Hoppers in whom most of the few African-American lindy hoppers/"swing dancers" have been interested are the Second Generation Savoy Lindy Hoppers Miller and Manning, and Sugar Sullivan from the Third Generation. Many other Savoy Lindy Hoppers, and their descendants have been ignored and forgotten.

The "white domination" is also supported by the "power structures" which the dance school, dance camp, and classbased teaching of the Lindy Hop creates and maintains by insulating the Lindy Hop for those who participate in those activities, instead of active local social dance scenes where "each one teaches one" without fee. Participating in the activities takes money. African-Americans' economic situation is not as good as whites' economic situation in the US in 2017. African-Americans' median income is only $60 \%$ of the whites' median income and a fourth of AfricanAmericans live below the poverty line compared to a tenth of whites.[54]

In that regard, the reasons for the lack of African American lindy hoppers, which Dr. Hancock presents on pages 136 and 137, do not convince me. He argues that the lack of marketing the Lindy Hop to African-American communities, the lack of images of African-American Lindy Hop, "complex and contradictory sentiments" circulating within racial groups, and the diversity based, for example, on class, age, and gender possibly affect the case. I agree that the insufficient marketing to African-Americans and the lack of images of the current African-American Lindy Hop count in the case, but the poverty-related structural problems are hard to overcome by only marketing positive images of African-American Lindy Hoppers. Also a tendency to fragment the "swing scene" into smaller dance events for different skill and age groups is contrary to the Savoy Ballroom practices and affects the "swing scene" as a whole.[55]

\section{Conclusion}

The biggest problem in Dr. Hancock's analysis is that he was an insider in the "swing dance" scene which he researched. The objectivity of the study is questionable because this insider status. He was an outsider when he researched the Steppin' scene in Chicago. His success in the Steppin' scene resembles Frankie Manning's observation of the Savoy Ballroom scene where "they never looked at your face, only at your feet", and asked "can you 
dance?'[56]. Concluding from Dr. Hancock's Steppin' story explained on the chapter 'Steppin' Out of Whiteness', the similar skill-based inclusiveness prevailed in the Steppin' scene.

However, I'm not entirely convinced that his carnal sociological approach worked in the way it was supposed to work because of his inadequate knowledge of the original Lindy Hop history was not the most solid ground for a serious research. In other words, because he was taught in the same type of classes which he criticized, that could explain the inadequate knowledge of the history: he was not taught and mentored by those who know "how it really was" as it has become clear in my sometimes harsh criticism.

The interviews that he conducted brought out new and interesting facts about the current "swing dance"/Lindy Hop scene, which can be used for the future research. I agree with him that the current scene does not replicate the original Lindy Hop scene, but I do not always agree on the reasons why these scenes are different.

Notes:

[1] First of them was Mura Dehn who came to New York in the beginning of the 1930s. See Harri Heinilä, An Endeavor by Harlem Dancers to Achieve Equality - The Recognition of the Harlem Based Jazz Dance Between 1921 and 1943 (Helsinki: Unigrafia, 2015), p. 37. Other remarkable scholars have been Marshall Stearns, Sally Sommer, and Terry Monaghan who came to New York with his Jiving Lindy Hoppers in 1985. See Norma Miller, Swing, Baby, Swing! When Harlem Was King...And The Music Was Swing! (Blurb Inc., 2009), p. 21. Other remarkable revivalists (not including all of them) who started in the 1980s, and who were looking for Old-time dancers in New York are Larry Schulz and Sandra Cameron, Margaret Batiuchok, Erin Stevens, Lennart Westerlund, Anders Lind, Henning Sörensen, Robert P. Crease, Paul Grecki, and Simon Selmon.

[2] Marshall and Jean Stearns, Jazz Dance - The Story of American Vernacular Dance (New York, New York: Da Capo Press, 1994 - originally published in 1968), p. 315.

[3] Ibid., p. 324.

[4] Ibid., p. 323.

[5] Heinilä 2015, pp. 137-138. See also Terry Monaghan, 'George Snowden', The Dancing Times, July 2004.

[6] Snowden's role as the creator of the Lindy Hop and as the Lindy Hopper who laid down the foundation for the success of the Lindy Hop is explained in detail in my dissertation. See Heinilä 2015, pp. 134-138 and 165-168. Also Terry Monaghan discusses Snowden's creator role and career in dancing. See Monaghan 2004.

[7] According to Stearns, Tap dancer Ray Bolger stated that he invented the Lindy Hop in 1927. See Stearns 1994., p. 323.

[8] Peter BetBasoo is the first researcher who brought out these Lindy Hop dances in his Lindy Hop and Argentine Tango, copyright Peter BetBasoo, published in the Internet, 2009. All the dances were named as 'Lindy Hop'. See BetBasoo 2009. The very first of the dances was 'Lindbergh Hop' with six basic steps, which was referred to as 'Lindy Hop' in the headline of the newspaper article. See ' Lindy 'Hop' ' Difficult Dance', Pittsburgh Gazette Times, May 25, 1927 , p. 3. There are no references to any African-American origin of the non-Harlem Lindy Hop dances.

[9] As it is arguable how many times it has actually been referred to in public that whites created the Harlem Lindy Hop, there have been at least two serious claims that whites created it. One was Ray Bolger's statement which was mentioned in footnote 7, and other was done by a Daily News authority who claimed in 1940 that a white dance teacher created the Lindy Hop. See Heinilä 2015, p. 194 and footnote 753. Dr. Hancock quotes Dorthea Ohl in Ohl's article in the 1956 Dance Magazine in which Ohl claims that the Lindy was born at the Savoy Ballroom by an anonymous dancer who shouted that he flied like Lindy, referring to Charles 'Lindy' Lindbergh's famous flight in May 1927. As Ohl explains, that was based on a legend. See Black Hawk Hancock, American Allegory: Lindy Hop and the Racial Imagination (Chicago, IL: University of Chicago Press, 2013), p. 12. There is no evidence for the story. 
[10] See Heinilä 2015, pp. 141 and 165-166. The naming of the Lindy Hop is discussed in Heinilä 2015, pp. 138-141 and Monaghan 2004.

[11] Howard Spring, 'Swing and the Lindy Hop: Dance, Venue, Media, and Tradition', American Music, Vol. 15, No. 2, Summer 1997, pp. 190 and 204.

[12] Dr. Hancock explains in his study, in particular, on page 15 that the Lindy Hop had been forty years in dormancy until it was revived in the 1980s. Otherwise see pages 13-14.

[13] See Heinilä 2015, p. 189. See also Terry Monaghan, “'Stompin’ At the Savoy” - Remembering, Researching and Re-enacting the Lindy Hop's relationship to Harlem's Savoy Ballroom', Dancing At The Crossroads. African Diasporic Dances in Britain. Conference Proceedings 1-2 August 2002, London Metropolitan University, 2005, pp. 49 and 70 (footnote 113).

[14] The competition mode of the Lindy Hop was maintained by the Harvest Moon Ball contests between 1935 and 1989. The performance mode was maintained the Savoy Lindy Hoppers-based groups like Sonny Allen and the Rockets and the Mama Lou Parks Dancers. See Monaghan 2002/2005, pp. 45-49 and Terry Monaghan, 'Crashing Cars \& Keeping the Savoy's Memory Alive', republished as 'Mama Lou Parks by Terry Monaghan' in https://authenticjazzdance.wordpress.com/2015/04/25/mama-lou-parks-by-terry-monaghan/ . Frankie Manning's comments about social dancing during his post office career see Frankie Manning and Cynthia R. Millman, The Ambassador of Lindy Hop (Philadelphia: Temple University Press, 2007), p. 218. About swing dancing in California between the 1950s and the 1960s see Tamara Stevens, with editorial contributions by Erin Stevens, Swing Dancing (Santa Barbara, California: Greenwood, 2011), pp. 139-142. Dean Collins continued his swing dance activities in the 1970s see 'Swing Dancers Yearn for Music of Big-Band Era', Los Angeles Times, October 15, 1972, p. 4. '3Rd Anniversary Celebration', Los Angeles Times, September 30, 1976, p. M1. According to the latter article, Dean Collins performed 'Lindy Hop' in 1976.

[15] See Manning and Millman 2007,p. 218.

[16] Monaghan 2002/2005, p. 57.

[17] This is discussed in my article, 'Swing Dance or Jazz Dance - A Few Words About the Use of the Terms', January 7, 2016, published in https://authenticjazzdance.wordpress.com/2016/01/07/swing-dance-or-jazz-dance-a-few-wordsabout-the-use-of-the-terms/

[18] Ibid.

[19] Stevens 2011, pp. 95-96. See also 'Swing Dancers Yearn for Music of Big-Band Era', Los Angeles Times, October 15, 1972, p. 4. '3Rd Anniversary Celebration', Los Angeles Times, September 30, 1976, p. M1. Jazz dance historian Peter Winquist Loggins claimed, when I discussed with him in 2017, that Dean Collins' dancing was called The Lindy, and not the Lindy Hop. However, the aforementioned Los Angeles Times article clearly states that Collins did 'Lindy Hop' in 1976.

[20] How much the West Coast dancers' terminology affected the New York dancers needs more research. I have discussed with one of the 1980s revivalists, Margaret Batiuchok, who explained to me, as based on her experience, that Old-timers used the terms 'lindy hop' and 'swing (dance)' interchangeably. There are Savoy Lindy Hoppers like Norma Miller who have used the terms interchangeably. On the contrary, Savoy dancer George Lloyd argued that he did swing dance in the 1980s because he did not do "set routines" which were included only in the Lindy Hop. He used to do those routines, and thus the Lindy Hop in the past. See Margaret Batiuchok, The Lindy. Submitted in partial fulfillment of the requirements for the degree of Master of Arts to the faculty of the Gallatin Division of New York University, May 16, 1988, George Lloyd interview by Margaret Batiuchok, DVD. How much the use of the term 'swing dance' by Savoy Old-timers actually has stemmed from the intention to keep up with the current terminology needs research as well.

[21] Frankie Manning's opinion of Jitterbug is supported by Louise 'Mama Lou' Parks Duncanson who also considered the Lindy Hop and Jitterbug as the same dance. See Monaghan 2002/2005, p. 57. Another Savoy Lindy Hopper Albert 'Al' Minns explained that a Jitterbug was a person who danced in a uncontrolled way. See Al Minns interview by the Swedish Swing Society in 1984. This can be found at https://www.youtube.com/watch?v=-6DlmqOWBlg . Minns' 
opinion is supported by Terry Monaghan who defines the term 'jitterbugs' as "raucous swing fans" who danced the Shag or did not dance at all. See Karen Hubbard and Terry Monaghan, 'Negotiating Compromise on a Burnished Wood Floor - Social Dancing at the Savoy' in Julie Malnig (editor), Ballroom, Boogie, Shimmy Sham, Shake - A Social and Popular Dance Reader (Champaign, Illinois: University of Illinois Press, 2009), p. 145 (footnote 35). The definitions do not take a stand on racial identity of the dancers who danced Jitterbug or were Jitterbugs.

[22] Monaghan 2005, p. 77. Chad Heap, Slumming - Sexual and Racial Encounters In American Nightlife - 1885 1940 (Chicago: The University of Chicago Press, 2009), p. 256. See also 'Now We Have The 'Jitter Bug', The New York Amsterdam News, December 6, 1933, p. 7 and Roi Ottey, 'This Hectic Harlem', The New York Amsterdam News, January 17, 1934, p. 9.

[23] See Heinilä 2015, p. 254.

[24] See 'Jitterbugs Set to Swing at Bronzeville', The Chicago Defender, October 8, 1938, p. 19 and 'Girl's Band Takes City', The Chicago Defender, January 15, 1944. These articles are only an example. The subject needs more research to find out how frequently the Chicago Savoy dancers were referred to by the term.

[25] See Terry Monaghan, 'The Chicago and Harlem Savoy Ballrooms - Different Cultures - Different Fortunes', Society of Dance History Scholars Conference Papers, Susan C. Cook, Compiler, 9-12 - June Northwestern University - Evanston, Illinois, published by Society of Dance History Scholars, 2005, p. 155.

[26] The New York Amsterdam News claimed in its article, by referring to the Chicago's Federal Theatre Project's Swing Mikado, that "the most popular dance would shame Whitey's Lindy Hoppers" without explaining exactly what was the dance. It was stated in the article that the "Chicago company can truck and lindy and swing with the best of "em". Thus, referring clearly that the Lindy Hop was one of the dances by which "the Chicago company" was able to challenge the best exponents of the Lindy. See 'WPA Show Upsets B'way Equilibrium', The New York Amsterdam News, March 11, 1939, p. 16.

[27] The success of Whitey's Lindy Hoppers is discussed in my dissertation, in particularly in chapters, 'The Savoy Ballroom Between 1926 and 1943', 'Savoy Lindy Hoppers' Second Generation Between 1934 and 1943', and 'Harvest Moon Ball and the Savoy Lindy Hoppers Between 1935 and 1943'. See Heinilä 2015. In the end of the 1930s, promoter Michael Todd tried to find Lindy Hoppers in Chicago for his Hot Mikado show on Broadway. He did not find any of the requisite standard, and he had to use Whitey's Lindy Hoppers for the show. See Monaghan 2005, p. 159.

[28] Manning and Millman 2007,p. 70.

[29] Norma Miller and Evette Jensen, Swingin' at The Savoy - The Memoir of A Jazz Dancer (Philadelphia: Temple University Press, 1996), p. 257.

[30] Heinilä 2015, pp. 122-123. See also Monaghan 2002/2005, p. 55.

[31] Joel Hall was interviewed in 1999 when the episode happened. His style was described "an intoxicating cocktail mix of hip jazz dance and modern dance infused with classical ballet". See 'Dancer/Choreographer Joel Hall Brings his Urban Jazz Dance to "Dance Chicago" , Hyde Park Citizen, November 25, 1999, p. 13. See for differences between "modern jazz dance" and "authentic" jazz dance Heinilä 2015, pp. 43-45.

[32] Modern dance was created by whites, although it was later developed also by African-Americans. A good presentation of the origins of Modern dance is Margaret Lloyd's The Borzoi Book of Modern Dance (New York, New York: Dance Horizons, 1974).

[33] See Heinilä 2015, pp. 330-331.

[34] Terry Monaghan argues that Hip Hop dancing is part of "authentic" jazz dance. See Terry Monaghan, 'Crashing Cars \& Keeping the Savoy's Memory Alive', republished as 'Mama Lou Parks by Terry Monaghan' in https://authenticjazzdance.wordpress.com/2015/04/25/mama-lou-parks-by-terry-monaghan/ . 
[35] The dancers are Harry Rosenberg (later Rowe), Ruth Rheingold and Jimmy Valentine. See Heinilä 2015, p. 171 and Peter Loggins, Jimmy Valentine, published on August 31, 2009 in http://jassdancer.blogspot.fi/2009/08/jimmyvalentine.html.

[36] See Monaghan 2002/2005, pp. 35-36. See also Heinilä 2015, pp. 17, 19-20, and 126.

[37] Warren Berry, one of the famous Berry Brothers, told in an interview how Nyas Berry commented Warren's incorrect timing by saying, "What is this, a white boy we got here." See Rusty E. Frank, 'Warren Berry', Tap! - The Greatest Tap Dance Stars and Their Stories - 1900 - 1955 (Da Capo Press, New York, 1994), p. 160. Also according to my experience, African-American dancers have commented other African-Americans with "white boy"-related phrases when others do not dance in a correct way. A famous African-American entertainer Ethel Waters stated that African-Americans usually rated white people's dancing inferior to African-Americans' dancing. See also Ethel Waters with Charles Samuels, His Eyes on the Sparrow - An Autobiography (New York, New York: Da Capo Press, 1992), p. 134.

[38] Hancock 2013, pp. 83-88.

[39] This is discussed in various forums. One of those discussions can be found at https://sports.vice.com/en_us/article/nzxepd/how-swing-dancing-faced-its-sexual-assault-scandal .

[40] See Joel Dinerstein, Swinging The Machine - Modernity, Technology, And African American Culture Between The World Wars (Amherst, Ma: University of Massachusetts Press, 2003), p. 265 and Harri Heinilä, 'A Great Weekend in Harlem', published in https://authenticjazzdance.wordpress.com/2013/05/19/a-great-weekend-in-harlem/ .

[41] Waters 1992, p. 134.

[42] Marshall Stearns explains that the basic step is "a syncopated two-step" which is currently known as a triple step, or a box step, which both accent "the offbeat". See Stearns 1994, p. 323.

[43] This is based on my experience on the dance floor and available videos of the current dancers on YouTube. Entertainer Dawn Hampton explained in the video what is the off beat. The video can be found on YouTube. See https://www.youtube.com/watch?v=tEny_nB5yyA .

[44] This commodification happened by the end of the 1920s when the Lindy Hop was danced socially in ballrooms, competed, and performed. See Heinilä 2015, pp. 144 and 165-166.

[45] Monaghan 2002/2005, p. 54.

[46] This statement is arguable and based on my own experience on the social dance floor. The statement needs more research.

[47] For example, George Snowden, Alfred Leagins, Albert Minns and Leon James had a dance school and they gave dance classes. See Terry Monaghan, 'Remembering "Shorty” “, The Dancing Times, July 2004, p. 51. Monaghan 2002/2005, pp. 35 and 64 (footnote 24). Heinilä 2015, p. 62. Along with the revival of the interest in the Lindy Hop, Savoy Lindy Hoppers like Frankie Manning, Sugar Sullivan, George Sullivan, Barbara Billups, Sonny Allen, Charlotte 'Mommy' Thacker have taught the Lindy Hop classes. See Monaghan 2002/2005, pp. 49-52 and Harri Heinilä, 'A Great Weekend in Harlem', published in https://authenticjazzdance.wordpress.com/2013/05/19/a-great-weekend-inharlem/.

[48] Monaghan 2002/2005, p. 54.

[49] See Robert P. Crease, 'Eunice Callen', Footnotes: November - December, 1989. Vol.4, No. 3, published by The New York Swing Society, New York.

[50] This claim is arguable and needs more research, but according to studies which are mentioned in this article, the claim is an obvious conclusion. It could also be argued that the Lindy Hop is still taught in communities, but only the nature of communities has changed. That is why I use the expression, 'this type of a communal aspect'. 
[51] Terry Monaghan and Mo Dodson, 'Has Swing Dance Been "Revived"?', Dancing in the Millennium, proceedings, 2000, p. 319. Terry Monaghan and Mo Dotson, 'Fusion: Globalising the Local and Localising the Global - The Case of The Lindy and Other Fusion Dances/Musics', c2am Congress on Research in Dance. Conference (34th : 2001 : New York University). Proceedings. vol. 1, p. 224.

[52] See Eddie-Q, 'Sonny Allen - From the Savoy to the Palladium', Salsa and More, unknown date, p. 15. I got a copy of this from Sonny Allen in 2013. He stressed that they were not "a feeling good generation", which emphasizes the seriousness of Savoy Lindy Hoppers.

[53] According to Terry Monaghan, one of the 1980s revivalists, the 1980s revivalists had a "stepaholics" goals to get information about the original Lindy Hop, and its steps and patterns, which could explain the enthusiasm. See Terry Monaghan and Mo Dodson 2000, p. 318. However, it is not known if he was one of those people in the room.

[54] See National Urban League - 2017 Equality Index - IHS Global Insight - 2017 State of Black America Protect Our Progress, p. 8.

[55] Monaghan 2002/2005, p. 54.

[56] Manning and Millman 2007,p. 71.

\section{Sources}

Bibliography

Articles

'Dancer/Choreographer Joel Hall Brings his Urban Jazz Dance to "Dance Chicago" ', Hyde Park Citizen, November 25, 1999.

'Girl's Band Takes City', The Chicago Defender, January 15, 1944.

'Jitterbugs Set to Swing at Bronzeville', The Chicago Defender, October 8, 1938.

'Lindy ‘Hop’ Difficult Dance', Pittsburgh Gazette Times, May 25, 1927.

'Now We Have The 'Jitter Bug', , The New York Amsterdam News, December 6, 1933.

Ottey Roy, 'This Hectic Harlem', The New York Amsterdam News, January 17, 1934.

'Swing Dancers Yearn for Music of Big-Band Era', Los Angeles Times, October 15, 1972.

' $3^{\text {Rd }}$ Anniversary Celebration', Los Angeles Times, September 30, 1976.

'WPA Show Upsets B'way Equilibrium', The New York Amsterdam News, March 11, 1939.

Audio \& Video

Margaret Batiuchok, The Lindy. Submitted in partial fulfillment of the requirements for the degree of Master of Arts to the faculty of the Gallatin Division of New York University, May 16, 1988, George Lloyd interview by Margaret

Batiuchok, DVD.

Hampton Dawn, regarding, see https://www.youtube.com/watch?v=tEny_nB5yyA .

Literature

BetBasoo Peter, Lindy Hop and Argentine Tango, copyright Peter BetBasoo, published in the Internet. 
Black Hawk Hancock, American Allegory: Lindy Hop and the Racial Imagination (Chicago, IL: University of Chicago Press, 2013).

Crease, Robert P., ‘Eunice Callen’, Footnotes: November - December, 1989. Vol. 4, No. 3, published by The New York Swing Dance Society, New York.

Dinerstein Joel, Swinging The Machine - Modernity, Technology, And African American Culture Between The World Wars (Amherst, Ma: University of Massachusetts Press, 2003).

Eddie-Q, 'Sonny Allen - From the Savoy to the Palladium', Salsa and More, unknown date.

Frank, Rusty E., 'Warren Berry', Tap! - The Greatest Tap Dance Stars and Their Stories - 1900 - 1955 (New York, New York: Da Capo Press, 1994).

Heinilä Harri, An Endeavor by Harlem Dancers to Achieve Equality - The Recognition of the Harlem Based Jazz. Dance Between 1921 and 1943 (Helsinki: Unigrafia, 2015).

Heinilä Harri, 'Swing Dance or Jazz Dance - A Few Words About the Use of the Terms', January 7, 2016, published in https://authenticjazzdance.wordpress.com/2016/01/07/swing-dance-or-jazz-dance-a-few-words-about-the-use-of-theterms/.

Heinilä Harri, ‘A Great Weekend in Harlem', published in https://authenticjazzdance.wordpress.com/2013/05/19/agreat-weekend-in-harlem/.

Heap Chad, Slumming - Sexual and Racial Encounters In American Nightlife - 1885 - 1940 (Chicago, IL: The University of Chicago Press, 2009).

Hubbard Karen and Terry Monaghan, 'Negotiating Compromise on a Burnished Wood Floor - Social Dancing at the Savoy' in Julie Malnig (editor), Ballroom, Boogie, Shimmy Sham, Shake - A Social and Popular Dance Reader (Champaign, Illinois: University of Illinois Press, 2009).

Lloyd Margaret, The Borzoi Book of Modern Dance (New York, New York: Dance Horizons, 1974).

Loggins, Peter, Jimmy Valentine, published on August 31, 2009 in http://jassdancer.blogspot.fi/2009/08/jimmyvalentine.html .

Manning Frankie and Cynthia R. Millman, The Ambassador of Lindy Hop (Philadelphia: Temple University Press, 2007).

Miller Norma, Swing, Baby, Swing! When Harlem Was King...And The Music Was Swing! (Blurb Inc., 2009).

Miller Norma and Evette Jensen, Swingin' at The Savoy - The Memoir of A Jazz Dancer (Philadelphia: Temple University Press, 1996).

Mitchell Steven, regarding, see https://sports.vice.com/en_us/article/nzxepd/how-swing-dancing-faced-its-sexualassault-scandal .

Monaghan Terry, 'The Chicago and Harlem Savoy Ballrooms - Different Cultures - Different Fortunes', Society of Dance History Scholars Conference Papers, Susan C. Cook, Compiler, 9-12 - June Northwestern University Evanston, Illinois, Published by Society of Dance History Scholars, 2005.

Monaghan Terry, 'Crashing Cars \& Keeping the Savoy's Memory Alive', republished as 'Mama Lou Parks by Terry Monaghan' in https://authenticjazzdance.wordpress.com/2015/04/25/mama-lou-parks-by-terry-monaghan/

Monaghan Terry, 'George Snowden’, The Dancing Times, July 2004.

Monaghan Terry and Mo Dodson, 'Has Swing Dance Been "Revived"?', Dancing in the Millennium, proceedings, 2000, p. 319. Terry Monaghan and Mo Dotson, 'Fusion: Globalising the Local and Localising the Global - The Case of The Lindy and Other Fusion Dances/Musics', c2am Congress on Research in Dance. Conference (34th : 2001 : New York University). Proceedings. vol. 1.'. 
Monaghan Terry, “'Stompin’ At the Savoy” - Remembering, Researching and Re-enacting the Lindy Hop's relationship to Harlem's Savoy Ballroom', Dancing At The Crossroads. African Diasporic Dances in Britain. Conference Proceedings 1-2 August 2002, London Metropolitan University, 2005.

National Urban League - 2017 Equality Index - IHS Global Insight - 2017 State of Black America Protect Our Progress, published in

http://soba.iamempowered.com/sites/soba.iamempowered.com/themes/soba/pdf/SOBA2017-black-white-index.pdf .

Spring Howard, 'Swing and the Lindy Hop: Dance, Venue, Media, and Tradition', American Music, Vol. 15, No. 2 , Summer 1997.

Stearns Marshall and Jean, Jazz Dance - The Story of American Vernacular Dance (New York, New York: Da Capo Press, 1994 - originally published in 1968).

Stevens Tamara, with editorial contributions by Erin Stevens, Swing Dancing (Santa Barbara, California: Greenwood, 2011).

Waters, Ethel with Charles Samuels, His Eyes on the Sparrow - An Autobiography (New York, New York: Da Capo Press, 1992).

Interviews

Albert 'Al' Minns, interview by the Swedish Swing Society in 1984 . This can be found at https://www .youtube.com/watch?v=-6DlmqOWBlg . 